\title{
Development of a Service Life Database of Building Elements Based on an International Data Collection
}

\author{
Kyriaki Goulouti, Morgane Giorgi, Didier Favre and Sébastien Lasvaux
}

Laboratory of Solar Energetics and Building Physics (IGT-LESBAT), HEIG-VD, University of Applied Sciences of Western Switzerland (HES-SO), Yverdon-les-Bains, Switzerland, sebastien.lasvaux@hes-so.ch

\begin{abstract}
This paper presents a new service life database (DUREE database) for building elements, based on international service life data. The database includes 7'000 service life data, for more than 2 '000 building elements. In addition, the fitting of the data to a lognormal distribution is presented. The study contributes to the increasing demand of probabilistic building LCA and LCC and provides the possibility to define statistical distributions, with a systematic way, for a large number of building elements and different levels of details (LOD), appropriate for BIM-based assessments.
\end{abstract}

Keywords: Service Life, LCA, LCC, Lognormal Distribution, Probabilistic Analysis.

\section{Introduction}

Reliability issues in life cycle studies, i.e. Life Cycle Assessment (LCA) or Life Cycle Cost (LCC) analysis have been long discussed (Björklund, 2002; Huijbregts, 1998). Different methods have been proposed to enhance the confidence in the LCA results, i.e. uncertainty and sensitivity analyses, as summarized in Pannier (2018) for the building sector. Reducing the variability and uncertainty of the input parameters, increase the accuracy of the LCA or LCC result. Among the different parameters that present significant uncertainty and influence the building LCA accuracy is the service life of the building elements, as it has been shown by different studies, e.g. (Grant and Ries, 2013). The service life mainly influences the use phase through the replacement of the building elements. For instance, in rescent LCA studies, the replacement stage can account for up to $36 \%$ of the greenhouse gas emissions (GHG) of a multifamily house (Goulouti et al., 2019).

The term 'service life' (or lifetime) can be understood and defined in various ways, depending on the scope of the final user e.g. building designer, owner, LCA or LCC expert (Lasvaux et al., 2019). According to Thiebat (2019), the service life of a building can be classified into physical, functional or economic service life. The physical service life corresponds to the lifetime allowed by physical degradation procedures, contrary to the functional one that additionally takes into account the 'performance/requirements ratio', while the economic service life corresponds to the residual economic value. Furthermore, the international standard ISO 15686, (ISO 15686:2011), distinguishes among the service life, the reference service life, the estimated service life, the predicted service life and the service life during the design. In the Swiss context, the Swiss Society of Architects and Engineers (SIA) differentiates the technical service life (SIA 2047, 2015; SIA 480, 2016), from the useful life (SIA 2047, 2015; SIA 260, 2003; SIA 480, 2016) or the amortization period (SIA 2032, 2010), used for LCA calculations. 
There are multiple studies, as summarized in Silvestre et al., (2015) that discuss the ways the service life is estimated, mainly through the deterministic, the probabilistic and engineering method. However, in practice, the attribution of the building elements service life is based on standardized values, from technical standards, as for example in Switzerland, in the SIA 2032 technical book (SIA 2032, 2010). Apart from the technical parameters that affect the duration of service life, different scientific studies, as summarized in (Goulouti et al., 2019; Volland et al., 2019) have identified a variety of non-technical, socio-economic parameters that additionally affect the service lives of building elements.

Hence, there is a variability linked to the definition and the corresponding estimation of service life and there is no general agreement about the service life data, among the studies, as it is also stated in Dixit (2017). Furthermore, in the literature, there are different ways of decomposing buildings and attributing the service life, i.e. either at the functional or at the construction material level. Previous studies with service life data for specific materials have been conducted by Hoxha et al. (Hoxha et al., 2014) and Dixit (2019), who additionally reported their variability through statistical distributions. Looking at more functional oriented databases, the Swiss eBKP-H - SN506511 (CRB, 2012) standard of construction costs provides a structured way to decompose the building into elements and sub-elements. Similar decomposition exists in Germany, too. In France, the INIES database that was developed to gather product-specific LCA studies of manufacturers (i.e. the "Environmental Product Declarations", EPDs), includes a hybrid building decomposition, combining both a functionoriented classification and a material orientation (e.g. firstly the Insulation product category,
which is then decomposed into different materials like EPS, glass wool, etc.). The main
limitations of the previous studies and databases are either that they are not complete, in terms
of material variety (Dixit, 2019; Hoxha et al., 2014) or that they report deterministic service
life values and no statistical distributions can be derived (CRB, 2012; HQF, 2004).
In the context of increasing the reliability in LCA and LCC calculations, by integrating the inherent uncertainties of the different parameters, there is a necessity of providing a systematic

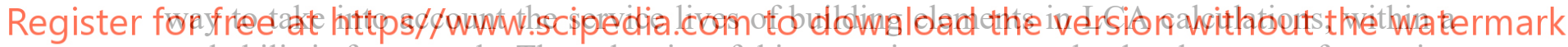
probabilistic framework. Thus, the aim of this paper is to present the development of a service life database that gathers service life data from 67 international sources. The database uses a hybrid decomposition (functional decomposition according to eBKP-H - SN506511 and material decomposition, as well) and it is thus compatible to the BIM-based LCA context, allowing calculations in different level of details (LOD), as stated in Cavalliere et al. (Cavalliere et al., 2018). Furthermore, statistical distributions are determined using the collected data, through a straightforward method.

\section{Development of the DUREE Service Life Database}

The literature search for service lives was conducted in English, French and German via Google, Google Scholar and Science Direct. The research of the service life data concerned data for the structural system, the technical installations, the façade elements and coatings, the roof elements, as well as for the interior layout. In total, 67 sources were identified, coming from energy standards, LCA and LCC standards, the public sector, scientific reports, private associations, banks, building management and insurance companies. Furthermore, the partners of the IEA EBC Annex 72 contributed to this research, by providing additional service life data 
through a survey, conducted on national LCA methodologies, in the beginning of 2019 (Lasvaux et al., 2019). Depending on the scope of the final user, the service life values were then classified in three main categories, i.e. LCA, LCC and Real - Estate Management. The 67 sources resulted in 95 entries and their allocation is presented in Table 1. Some documents did not only provide a single average service life but also a range of values e.g. min - mean - max. These values were treated as individual sources. Moreover, some service lives can be used in more than one category (e.g. LCA and LCC). In that case, the values were attributed to both LCA and LCC categories. This explains why the total number of sources in Table 1 is above 67. More details about the sources can be found in (Lasvaux et al., 2019).

Table 1. Type and number of identified sources and service life values.

\begin{tabular}{|l|l|l|}
\hline Type of sources & Total sources & Total values \\
\hline LCA documentations & 39 & 50 \\
\hline LCC analysis & 14 & 23 \\
\hline Real - Estate Management domain & 23 & 36 \\
\hline
\end{tabular}

The service life data were organized in a database and formed the DUREE Database in an Excel spreadsheet, according to the eBKP-H - SN506511 that it is appropriate for different LOD calculations, in BIM-based LCA and LCC analyses. The five main groups of building elements, extracted from this functional nomenclature, include the structural work (main group C), the technical installations (main group D), the façade elements and coatings (main group $\mathrm{E})$, the roof elements (n main categories are fur nomenclature (e.g. the 1 . sub-categories were adi detailed components. Figure 1 presents an exann LCA perimeter. The names of the eBKP-H - SN506511 codes of the building elements are Register forofreenatitutteps//www.scipedia.com to download the version without the watermark

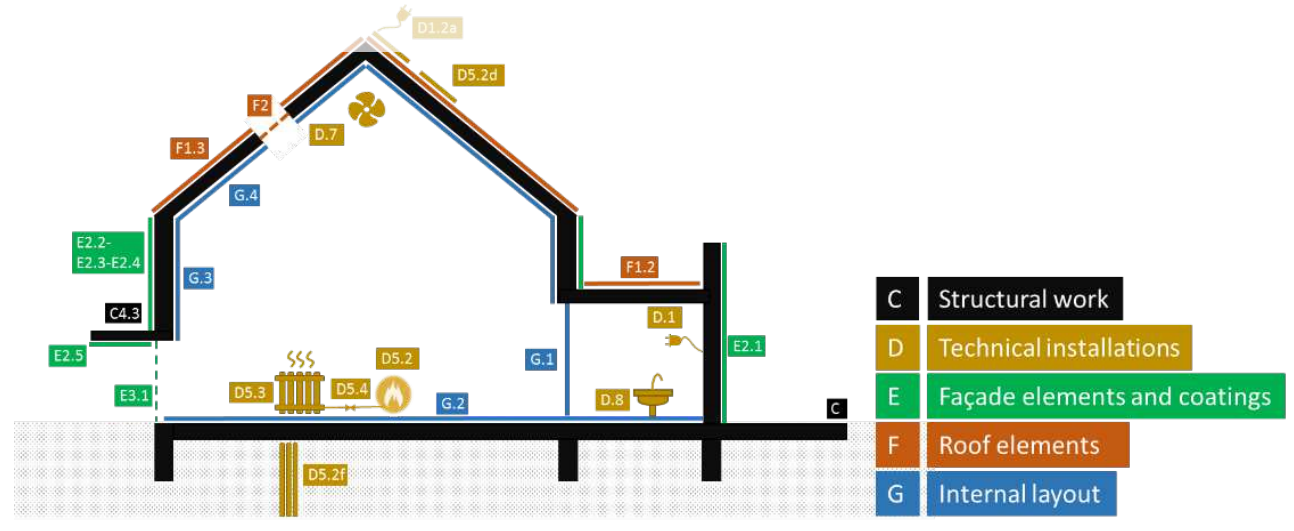

Figure 1. Main groups and intermediate element levels from the eBKP-H - SN 506511 nomenclature, for the 24 building elements, according to SIA 2032.

Each one of the 67 sources provides service life data for different components. Some sources offer data only for the main and intermediate categories, while others provide values at a lower 
material level. Hence, an Excel function was created in order to calculate the statistic mean for each source for the main and intermediate categories, in case that service live data were provided at the material level. This function adds a flexibility to the database and allows calculations for the different stages of the design process, i.e., for a screening analysis by taking values from the main categories (e.g. D Technical installations), or for a detailed analysis, by taking values from lower levels of details (e.g. heat producer, D5.2).

\section{Descriptive Statistics}

The database includes approximately 7'000 service lives data, for more than 2000 building elements. From these data, approximately $79 \%$ came from LCA and LCC sources. In addition, approximately $28 \%$ came from Switzerland and the rest were international data, mostly from European countries. The majority of Switzerland's data came from the management sector, while the majority of the international data belonged to the LCA domain.

Figure 2 presents the boxplots of the service lives for all the building elements included in the LCA perimeter of the Swiss SIA 2032 (see Figure 1). The descriptive statistics are presented for the total sample, as well as for the three sub-samples that correspond to service lives coming from LCA, LCC or Management sources. For some components such as photovoltaics, solar collectors or geothermal probes, some sub-samples (e.g. service life data for PVs in the LCC literature) are quite small, since there is a limited number of data found in the literature. The boxes correspond to the central $50 \%$ of the data, while the whiskers represent $80 \%$ of the data.

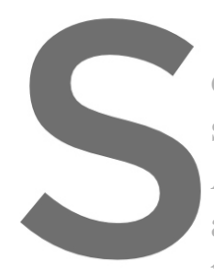

In general, there is

different sources do not service life data exhibit

As far as the median accordance, but they that presents systematically lower or higher van
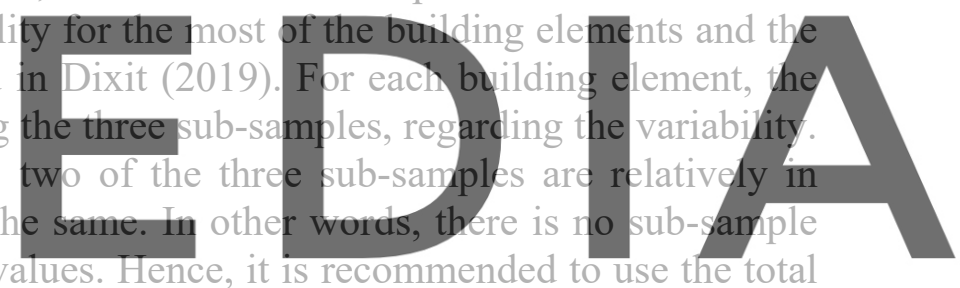
sample, in order to determine a statistical distribution for the building elements' service life.

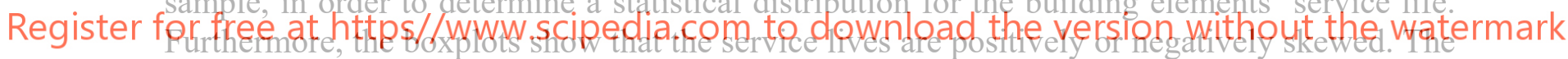

building elements exhibiting the highest variability are the technical installations (main group

D), while the smaliest variability is exhibited by the roof elements, (main group F). Furthermore, it should be noted that the variability of the sources diminishes, when moving towards lower levels of the database and more detailed materials, e.g. from D1 (electrical installations) to D1.2a (PV). The descriptive statistics for additional building elements can be found in (Goulouti et al., 2019). 


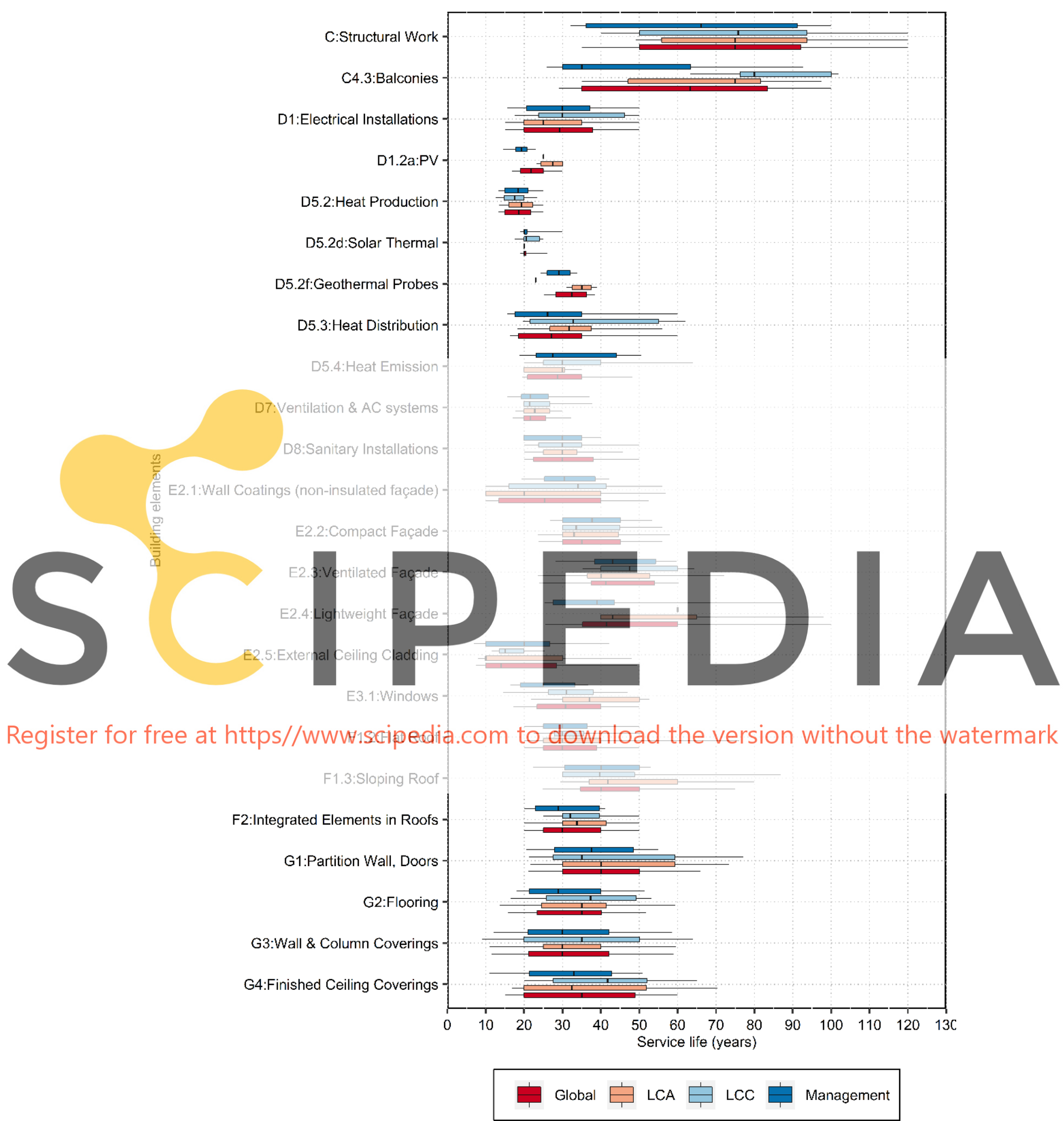

Figure 2. Boxplots for the 24 building elements, according to the SIA 2032 (see Figure 1) building LCA system boundaries. 


\section{Fitting to a Statistical Distribution}

As stated in Dixit (2017), in order to deal with the variability of the service lives, statistical distributions can be determined, based on empirical service life data. Thus, using the DUREE database, such statistical distributions can be derived, with a systematic way for different building elements and levels of the database, i.e. service lives coming from the main groups or the sub-categories. Consequently, the service lives of the building elements can be taken into account, within a probabilistic framework, in further LCA and LCC calculations. In the literature, the lifetime data are often modelled using lognormal or Weibull distributions, (Aktas and Bilec, 2012; Kim and Yum, 2008). Input service life data constitute independent positive random quantities, for which the use of the lognormal process is well justified, (Voelkel, 2006), since according to the central limit theorem in the log domain, an infinite number of positive random values would approach the lognormal distribution (Limpert et al., 2001). Thus, the latter can be used to model the service lives of building elements. In order to assess the goodness of fit of the lognormal distribution, two statistical methods were employed for the service lives of the building elements, using the statistical software R (R, 1997). First, the graphical method was computed, i.e. the Q-Q plots, which compares the theoretical and empirical distributions.

Figure 3 presents the empirical and theoretical density as well as the Q-Q plot of building element E.2 (Façade coatings above ground). The two graphs show that the two distributions are linearly related and that their points lie approximately on the line $y=x$. In addition, the $p$ value, according to the Anderson - Darling Test was calculated (R Documentation, 2002). The
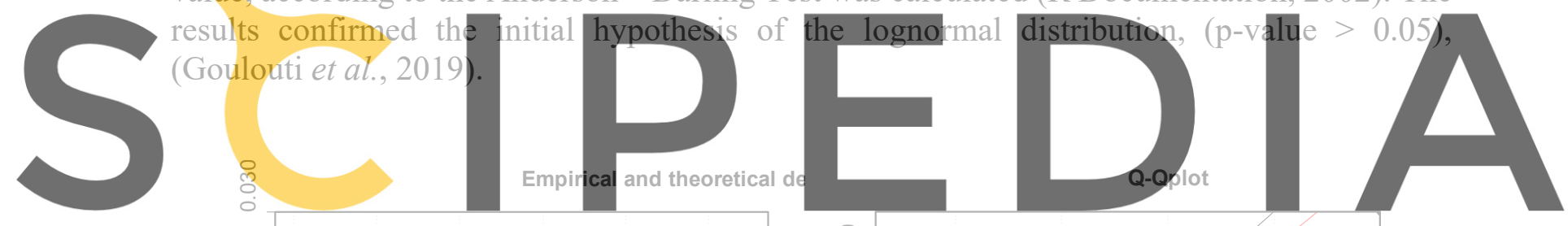

Register for frèe at https//www.scipedia.com to
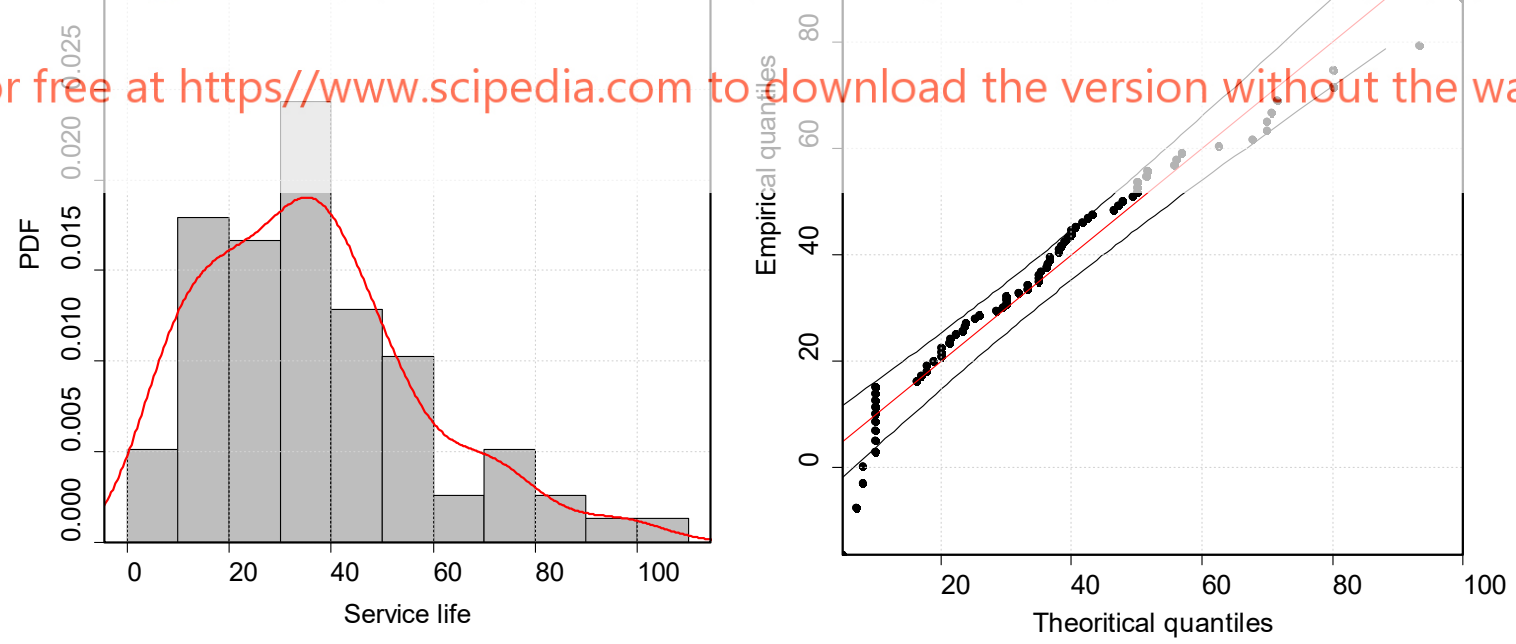

Figure 3. Example of goodness of fit (Q-Q plot) for the E.2 building element (Façade coating above ground). 


\section{Conclusions}

This paper presents the development of a new database (DUREE database) for the service lives of building elements. International service life data were gathered and classified in three subsamples, according to the scope of the sources application (LCA, LCC and Management sector). The main conclusions of the study are:

- The descriptive statistics show that there is a relative important variability and no general agreement, concerning the service lives of the building elements;

- There is no significant difference, among the three sub-samples, in terms of variability. As far as the median values are concerned, two of the three sub-samples present similar values, but they are not systematically the same. Thus, the total sample can be used in further LCA analysis;

- The structure of the database, i.e. main groups or sub-categories, offers the flexibility to the designer to attribute the service life data in different LODs, appropriate for BIMbased LCA analysis, e.g. screening LCA analysis (service lives from main groups), or more detailed LCA (service lives from sub-categories);

- The database offers the possibility to define statistical distributions, with a systematic way, for the service lives of the building elements. The goodness of fit for the different building elements confirmed the initial hypothesis of the lognormal distribution.

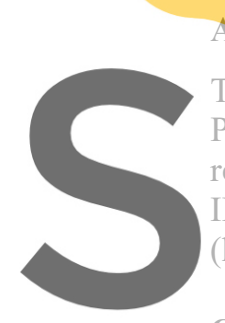

Acknowledgements
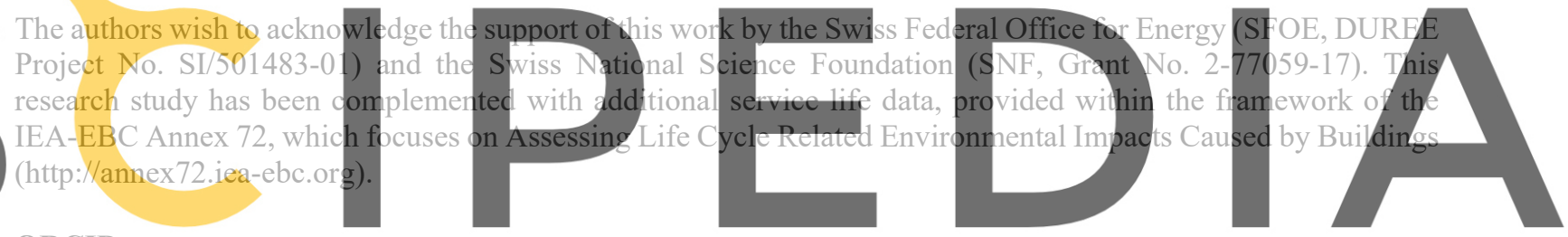

ORCID

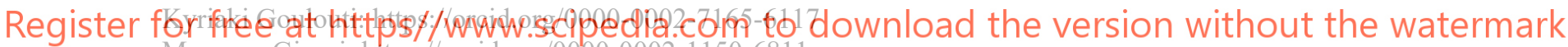

Morgane Giorgi: https://orcid.org/0000-0002-1150-6811

Didier Favre: https://orcid.org/0000-0002-3351-2710

Sébastien Lasvaux: https://orcid.org/0000-0002-8723-9676

\section{References}

Aktas, C. B., and Bilec, M. M. (2012). Impact of lifetime on US residential building LCA results. International Journal of Life Cycle Assessment, 17(3), 337-349. https://doi.org/10.1007/s11367-011-0363-x

Björklund, A. E. (2002). Survey of approaches to improve reliability in LCA. International Journal of Life Cycle Assessment, 7(2), 64-72. https://doi.org/10.1007/BF02978849

Cavalliere, C., Habert, G.,Dell'Osso R. and Hollberg, A. (2018). Continuous BIM-based assessment of embodied environmental impacts throughout the design process. Journal of Cleaner Production.

CRB. SN 506511, Code des coûts de construction Bâtiment. , (2012).

Dixit, M. K. (2017). Life cycle embodied energy analysis of residential buildings: A review of literature to investigate embodied energy parameters. Renewable and Sustainable Energy Reviews, 79, 390-413. https://doi.org/10.1016/j.rser.2017.05.051

Dixit, M. K. (2019). Life cycle recurrent embodied energy calculation of buildings: A review. Journal of Cleaner Production, 209, 731-754. https://doi.org/10.1016/J.JCLEPRO.2018.10.230

Goulouti, K., Padey, P., Galimshina, A., Habert, G. and Lasvaux, S. (2020). Uncertainty of building elements' service lives in LCA \& LCC of buildings: What matters? Building and Environment,183, https://doi.org/10.1016/j.buildenv.2020.106904 
Grant, A. and Ries, R. (2013). Impact of building service life models on life cycle assessment. Building Research and Information, 41(2), 168-186. https://doi.org/10.1080/09613218.2012.730735

Hoxha, E., Habert, G., Chevalier, J., Bazzana, M. and Le Roy, R. (2014). Method to analyse the contribution of material's sensitivity in buildings' environmental impact. Journal of Cleaner Production, 66, 54-64. https://doi.org/10.1016/j.jclepro.2013.10.056

HQE. (2004). INIES, Environmental and health reference data for building. Retrieved July 9, 2019, from https://www.inies.fr/about-the-inies-database/

Huijbregts, M. A. J. (1998). Uncertainty in LCA LCA Methodology Application of Uncertainty and Variability in LCA. The International Journal of Life Cycle Assessment, 3(5), 273-280.

ISO/TC 59/SC 14. ISO 15686-1:2011:Buildings and constructed assets - Service life planning. , (2011).

Kim, J. S. and Yum, B. J. (2008). Selection between Weibull and lognormal distributions: A comparative simulation study. Computational Statistics and Data Analysis, 53(2), 477-485. https://doi.org/10.1016/j.csda.2008.08.012

Lasvaux, S., Giorgi, M., Lesage, J., Wagner, G., Favre, D., Padey, P., ... Habert, G. (2019). DUREE Project, Analysis of lifetimes of building elements in the literature and in renovation practices and sensitivity analyses on building LCA \& LCC. Retrieved from https://www.aramis.admin.ch/Texte/?ProjectID=38626

Limpert, E., Stahel, W. A.and Abbt, M. (2001). Log-normal Distributions. 51(5), $341-352$. https://doi.org/10.1641/0006-3568(2001)051[0341:LNDATS]2.0.CO;2

Pannier, M. L., Schalbart, P. and Peuportier, B. (2018). Comprehensive assessment of sensitivity analysis methods for the identification of influential factors in building life cycle assessment. Journal of Cleaner Production, 199, 466-480. https://doi.org/10.1016/j.jclepro.2018.07.070

R. (1997). The R Project for Statistical Computing.

R Documentation. (2002). Anderson-Darling Test For Normality. Retrieved March 31, 2019, from https://www.rdocumentation.org/packages/nortest/versions/1.0-4/topics/ad.test

SIA 2032. (2010). SIA 2032 - L’énergie grise des bâtiments. Zürich: Société Suisse des Ingénieurs et des Architectes (SIA).

SIA 2047. (2015). SIA 2047 Architectes (SIA).

SIA 260. (2003). SIA 260 Ingénieurs et des Architect
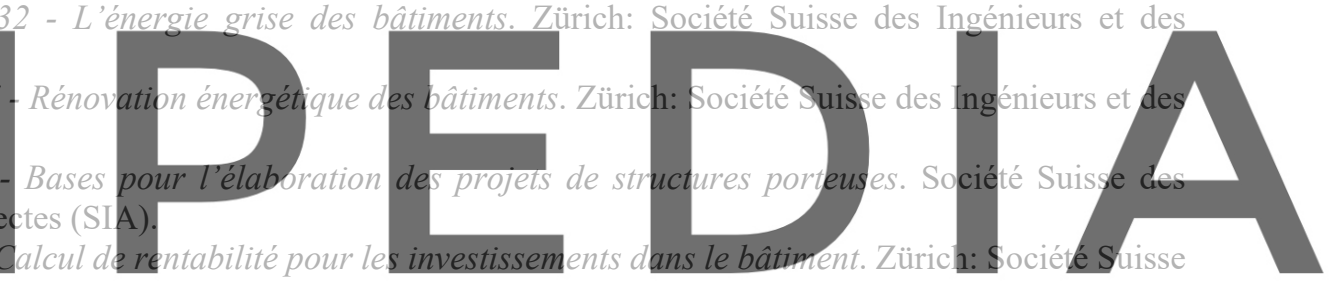
des Ingénieurs et des Architectes (SIA).

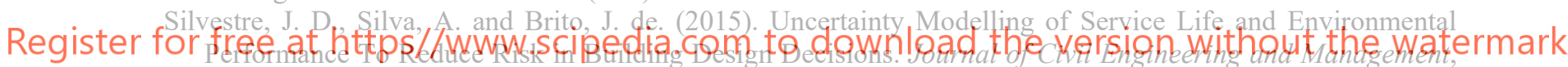
21(3), 308-322. https://doi.org/10.3846/13923730.2014.890649

Thiebat, F. (2019). Life Cycle Design, An Experimental Tool for Designers. Springer IInternational Publishing.

Voelkel, J. G. (2006). Weibull vs Lognormal Data Analysis.

Volland, B., Farsi, M., Lasvaux, S. and Padey, P. (2019). Service life of building elements: An empirical investigation. In Progress. 